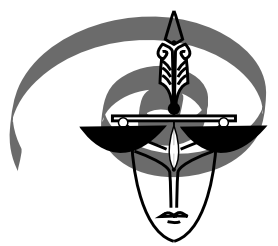

EUROPEAN

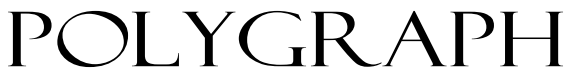

Volume $10 \cdot 2016 \cdot$ Number $3(37)$

DOI: 10.1515/ep-2016-0019

\title{
International Society of Polygraph Examiners (ISOPE) 1st International Seminar Guatemala City, Guatemala
}

The first international seminar of ISOPE was held in Guatemala City, on 16-19August, with 60 participants from Guatemala, Honduras, Mexico, Nicaragua, Costa Rica, and the United States. It was hosted by Grupo R\&T of Guatemala, with support from the Lafayette Instrument Company.

Dedicated to the enhancement of the polygraph profession throughout the world by providing standards of practice, validated polygraph techniques, instrumentation, published research ethical conduct, progressive training seminars and continued education in the field of forensic psychophysiology, ISOPE was formed in 2013. The Society's membership criteria, bylaws, and standards are a lodestar for all practicing professional examiners, and the opportunity to participate helps to upgrade their skills.

Members receive access to European Polygraph, a journal edited by Professor Jan Widacki, and to the ISOPE Research Digest, edited by James Matte.

Lectures were delivered by Nathan J. Gordon, President of ISOPE, Tuvia Shurany, Vice President of ISOPE, and Yazmin Bronkema of the Lafayette Instrument Company. The first lectured on technique development with focus on the Backster family of techniques: Backster You Phase, Federal Zone, Air Force Zone, Matte Quadri- 
Track, Utah Zone, and Integrated Zone. He also presented the Morgan Interview Theme Technique and Forensic Statement Analysis. Mr. Shurany's presentations included the Backster Zone and psychological concepts, including his recent research published in European Polygraph and demonstrating that the anti-climax dampening concept does in fact exist, the Concealed Information Test, Polygraph Validation Test, and Countermeasures and Counter-counter measures. Ms Bronkema presented Lafayette's most recent software (version 11.6), and covered some of the changes in the new application and its operation.

Grupo R\&T did an excellent job in hosting the event. A booth was set up for interpretation between Spanish and English, with Fabiola Chaves, a polygrapher from Lie Catcher (Costa Rica) helping to bridge the language gap. The participants listened intensely to the lectures and tried to absorb as much as possible to enhance their professional skills in the art of truth validation. Many attendees decided to join ISOPE during the event.

Future seminars are now being planned throughout Europe, the US, and Africa. 